\title{
Facial nerve palsy after orthognathic surgery caused by a hemoclip
}

\author{
Hojune Lee*, Ye Seul Eom*, \\ Goo-Hyun Mun, So Young Lim \\ Department of Plastic Surgery, Samsung \\ Medical Center, Sungkyunkwan \\ University School of Medicine, Seoul, \\ Korea
} ${ }^{*}$ The two authors contributed equally to this
work.

\begin{abstract}
Reduction mandibuloplasty is one of the most frequently performed aesthetic surgical procedures in Korea. Cases of facial nerve injury after mandibuloplasty have been reported, but most of those cases have not been clearly presented in detail. This report describes the case of a 38-year-old patient who underwent reduction mandibuloplasty at a local plastic surgery clinic. A massive bleeding event occurred during surgery, and hemostasis was performed by a surgeon at the local clinic. During an exploratory procedure, we found that the facial nerve trunk was clipped with a metallic hemoclip. We then straightened the pressed epineurium to its original shape under surgical microscopy. Oral prednisolone administration began on the first day after the procedure and was gradually tapered off. The patient showed some improvement after 7 weeks and showed $80 \%$ to $90 \%$ improvement after 5 months.
\end{abstract}

Keywords Mandibular osteotomy / Facial nerve injury / Complications / Case report

\section{INTRODUCTION}

Reduction mandibuloplasty has gained popularity for cosmetic applications in Korea as a result of the growing perception that a square face lends a rough and masculine appearance. Reduction mandibuloplasty is one of the most frequently performed surgical procedures in Korea. However, some complications of reduction mandibuloplasty have been reported, such as inferior lip numbness, hematoma, infection, severe swelling, scarring in the corner of the mouth, mental nerve injury, secondary angle formation, permanent facial nerve injury, asymmetry, subcondylar fracture, and massive bleeding [1-3]. Abnormal sensation due to injury of the inferior alveolar nerve is a relatively common neurological complication; in contrast, facial nerve injury is less common but is one of the most critical complications. Cases of facial nerve injury

Received: Aug 6, 2019 Revised: Sep 4, 2019 Accepted: Sep 9, 2019 Correspondence: So Young Lim Department of Plastic Surgery, Samsung Medical Center, Sungkyunkwan University School of Medicine, 81 Irwon-ro, Gangnam-gu, Seoul 06351, Korea

Tel: +82-2-3410-2239, Fax: +82-2-3410-0036, E-mail: pslisy@naver.com

Copyright @ 2020 The Korean Society for Aesthetic Plastic Surgery.

This is an Open Access article distributed under the terms of the Creative Commons Attribution Non-Commercial License (https://creativecommons.org/licenses/by-nc/4.0/) which permits unrestricted non-commercial use, distribution, and reproduction in any medium, provided the original work is properly cited. www.e-aaps.org after mandibular contouring have been reported [1-3], but the course of recovery of most cases was not clearly described. Here, we report a complicated case that required exploratory surgery for facial nerve palsy after reduction mandibuloplasty.

\section{CASE REPORT}

A 38-year-old man visited our outpatient clinic to consult a surgeon, as he was unable to fully move the right corner of his mouth, making it necessary to rule out hemifacial nerve palsy. A day before this visit, the patient underwent reduction mandibuloplasty at a local plastic surgery clinic. The surgeon who performed the procedure suspected an acute nerve injury, and he waited for a day for the patient's condition to improve spontaneously. However, the patient's condition did not improve, and he was referred to a general hospital for treatment of the peripheral nerve injury.

The surgeon reported that a massive intraoperative bleeding event occurred during dissection of the right mandibular periosteum via the intraoral approach. For clearer visualization, he performed an additional retromandibular incision while exploring the bleeding focus. Hemostasis was obtained, but immediately after the procedure, the patient's facial expression, especially the right corner of his mouth, looked unnatural.

Physical examination noted no obvious facial disfiguration at rest, but the muscle function of the right hemiface was impaired. 

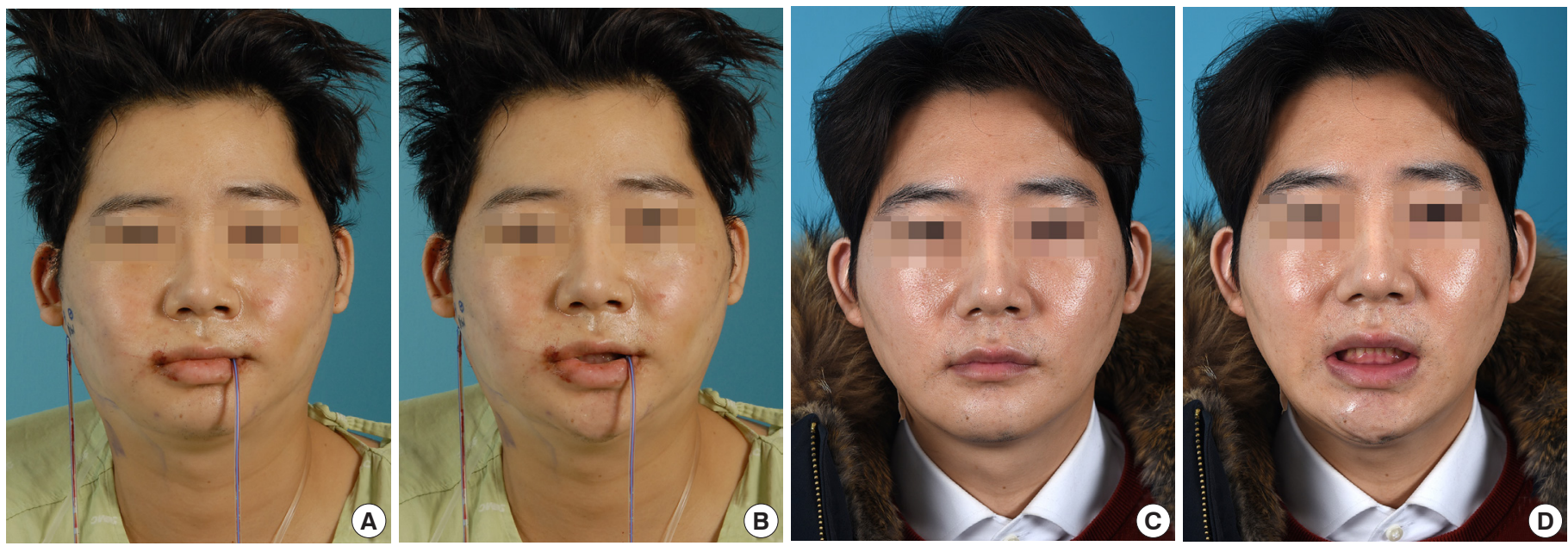

Fig. 1. Photographs of the patient 1 day $(A, B)$ and 8 weeks $(C, D)$ after reduction mandibuloplasty, showing slight facial asymmetry secondary to right facial palsy. The right eyebrow ptosis, right-sided flat nasolabial fold, and drooping of the right corner of the mouth showed obvious improvement after 8 weeks.

Motor NCS FACIAL - oris
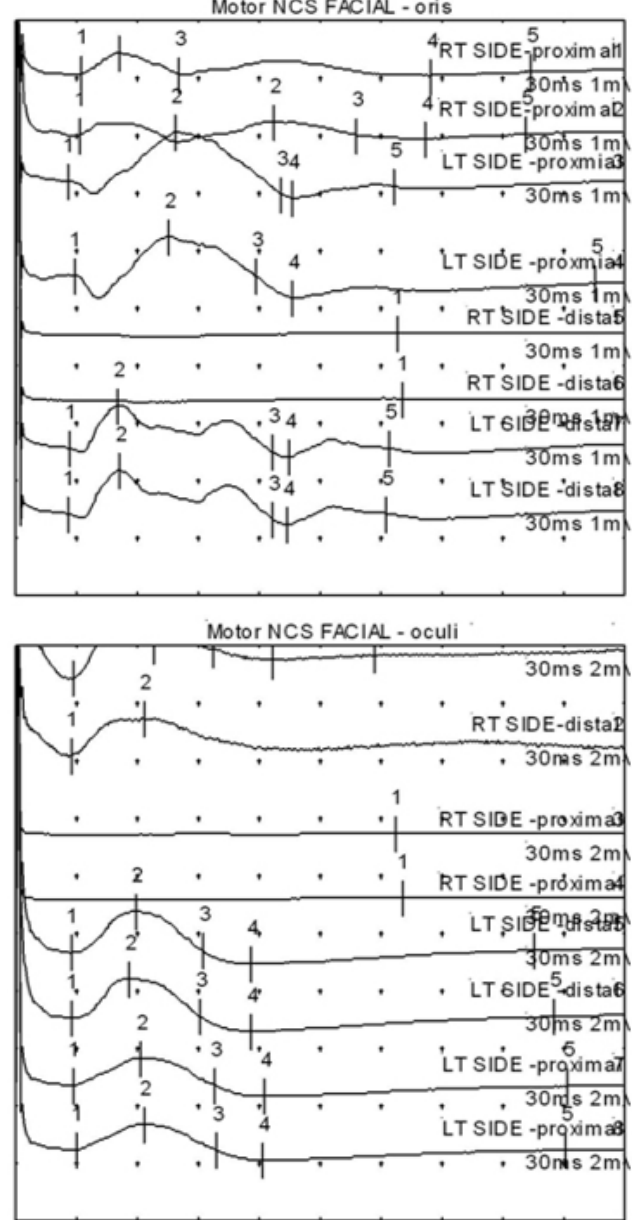

Motor NCS FACIAL - nasalis

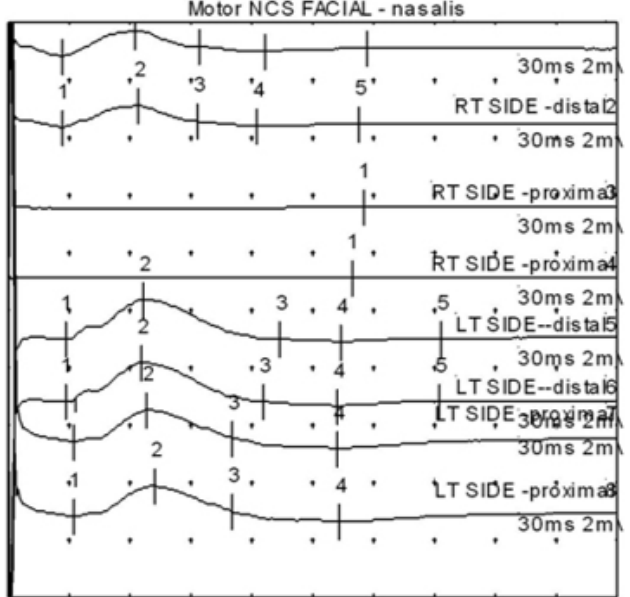

Motor NCS FACIAL - frontalis

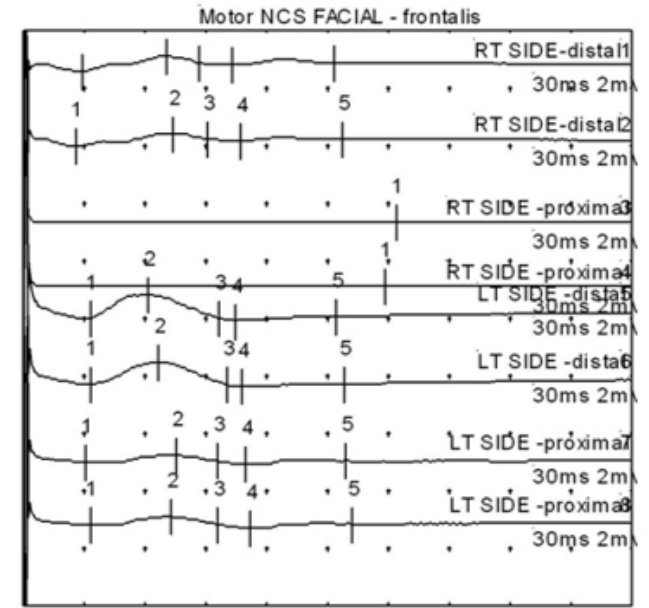

Fig. 2. Results of a nerve conduction study (NCS) indicated right facial neuropathy. The compound muscle action potential amplitude on the right hemiface shows obvious impairment compared to the left side, and a nerve conduction block is seen within the mandibular incision line. RT, right; LT, left. 

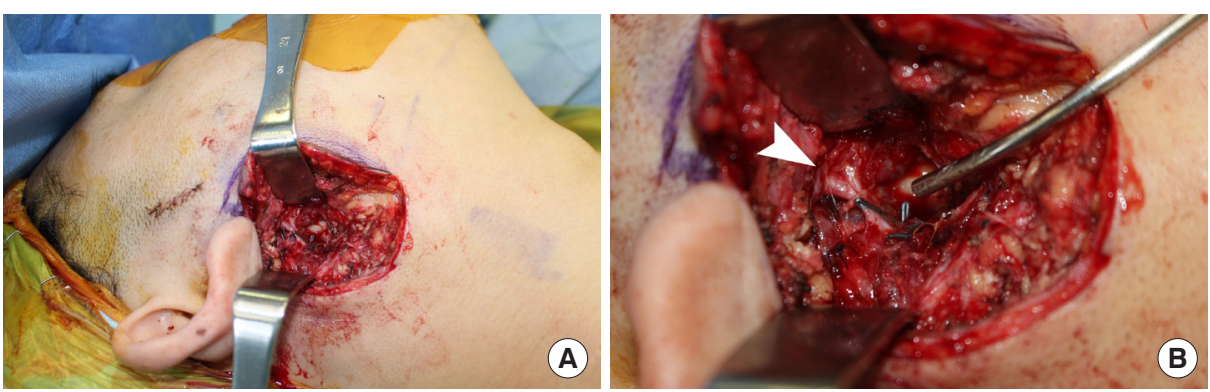

Fig. 3. (A-C) Photographs during an exploratory procedure. The facial nerve trunk is shown to be clipped with a metallic hemoclip ( $\mathrm{B}$, white arrowhead), which was then released and straightened to its original shape (C).

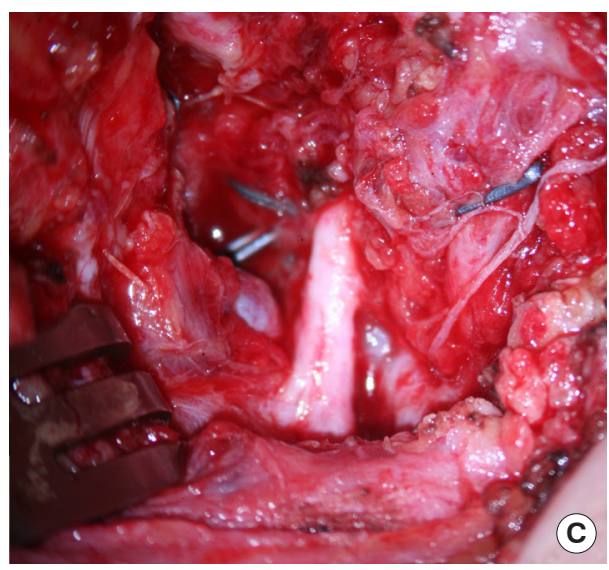

The patient's face showed brow ptosis, decreased wrinkling of the right hemiface, an asymmetrical smile, and the requirement of additional effort to open and close the eyes. The sensory function of the right hemiface was only $70 \%$ of that of the left hemiface, according to the patient (Fig. 1).

An exploratory procedure was planned on postoperative day 2, and the results of a nerve conduction study indicated right facial neuropathy. A change in compound muscle action potential amplitude was observed on the right hemiface, with an impairment ranging from $44 \%$ to $66 \%$, and a nerve conduction block was noted within the mandibular incision line (Fig. 2).

With the patient under general anesthesia, using endotracheal intubation, the right preauricular sutured wound was opened with an additional incision parallel to the body of the mandible. After the incision was deepened, the soft tissues were carefully dissected to avoid injury to the facial nerve. A nerve stimulator was used to locate the facial nerve during dissection. Many metallic hemoclips were found in the field, indicating the difficulty of obtaining hemostasis during the previous procedure. Dissection was performed from the tragal area in the medial direction to follow the passage of the facial nerve. The hemoclips were carefully removed to release the clipped tissue, and meticulous hemostasis using bipolar electrocautery was simultaneously performed. After fine dissection and clearance of the field of vision, the facial nerve trunk was observed to be clipped with a hemoclip. The hemoclip was removed, and the facial nerve was closely examined under surgical microscopy. The pressed epineurium was carefully straightened to its original shape (Fig. 3). We observed a right nostril movement during nerve stimulation, indicating recovery of the nerve conduction block. One silastic drain was inserted, and the wound was closed layer by layer. The patient received $48 \mathrm{mg}$ of methylprednisolone from postoperative day 1 to day 7 , and the medicine was tapered until postoperative day 12. He was discharged from the hospital 7 days after the procedure.

At a follow-up appointment 7 weeks after the exploratory procedure, decreased compound muscle action potential amplitude was still noted in the right hemiface, but a nerve conduction study indicated some improvement in the blockage of nerve conduction. The patient's gross appearance showed substantial improvement 8 weeks after the operation (Fig. 1). Most of the facial muscles had regained their function except for the frontal branch, which still showed an impairment of $10 \%$ to $20 \% 5$ months after the procedure.

\section{DISCUSSION}

Reports of complications of facial nerve palsy after mandible reduction surgery are scarce, and as such, those reports have not been highlighted. In 2014, Kang [3] reported cases of nerve injury associated with mandibuloplasty but focused on neurosensory deficits. Recently, Shimada et al. [4] reported cases of facial nerve palsy after bilateral sagittal split ramus osteotomy, most of which developed within 3 days after surgery. Several factors can cause facial nerve damage during or after reduction mandibuloplasty, including the compression of nerves by retractors, postoperative edema or hematoma, pressure packing in the retromandibular region, and unusual fractures of the mandible or styloid process [4-9]. However, this case suggests that, to avoid facial nerve injury, blinded hemoclips should not be used. As facial nerve injury is a severe complication, care must be taken while using a hemoclip to prevent this unwanted event.

Traumatic facial nerve injury may cause perineural edema, which can result in nerve degeneration. It is well known that approximately 3 days are needed for Wallerian degeneration to occur [10]. In this case, although only 2 days had passed after orthognathic surgery, some degree of degeneration may have progressed, as shown by the results of a nerve conduction study in combination with the prolonged healing time of the patient. Based on an experiment using a rat model, Omura et al. [11] and Kitao et al. [12] reported that acute compression with a hemoclip may cause neurapraxia, which was observed to recover within 2 weeks. However, in those reports, hemoclips were applied to the nerves of the rats for only 10 
and 5 minutes, respectively. The delayed functional recovery observed in our case as compared with previous reports may have been caused by the prolonged duration of the clipped state of the nerve or by mixed nerve injuries that included more than neurapraxia alone. If the surgeon from the local clinic had underestimated or overlooked the patient's condition, the patient would likely have had longer-lasting or even permanent sequelae.

At a follow-up appointment 7 weeks after the exploratory procedure, the patient's clinical condition had improved, but the patient still displayed an awkward right hemiface when making certain facial expressions, such as smiling. The results of the nerve conduction study also indicated that facial nerve function had not fully recovered. Sun et al. [10] reported that return of facial nerve function should not be expected for weeks to months after decompression surgery and may be delayed up to 12 months. However, in the case of the patient in our study, most of the right facial muscle function had been regained by 5 months after the exploratory procedure.

\section{NOTES}

\section{Conflict of interest}

No potential conflict of interest relevant to this article was reported.

\section{Ethical approval}

The study was performed in accordance with the principles of the Declaration of Helsinki.

\section{Patient consent}

The patient provided written informed consent for the publication and the use of his images.

\section{ORCID}

Hojune Lee

https://orcid.org/0000-0001-5226-1825

Ye Seul Eom

https://orcid.org/0000-0002-3202-5873

Goo-Hyun Mun

https://orcid.org/0000-0003-3481-7978

So Young Lim

\section{REFERENCES}

1. Yoon ES, Seo YS, Kang DH, et al. Analysis of incidences and types of complications in mandibular angle ostectomy in Koreans. Ann Plast Surg 2006;57:541-4.

2. Chen H, Sun J, Wang J. Reducing prominent mandibular angle osteotomy complications: 10-year retrospective review. Ann Plast Surg 2018; 81(6S Suppl 1):S5-9.

3. Kang M. Incidence of complications associated with mandibuloplasty: a review of 588 cases over 5 years. Plast Reconstr Surg Glob Open 2014; 2:e139.

4. Shimada Y, Kawasaki Y, Maruoka Y. Peripheral facial palsy after bilateral sagittal split ramus osteotomy: case report. Br J Oral Maxillofac Surg 2019;57:260-4.

5. Dendy RA. Facial nerve paralysis following sagittal split mandibular osteotomy: a case report. Br J Oral Surg 1973;11:101-5.

6. Rai KK, Shivakumar HR, Sonar MD. Transient facial nerve palsy following bilateral sagittal split ramus osteotomy for setback of the mandible: a review of incidence and management. J Oral Maxillofac Surg 2008;66:373-8.

7. Surpure S, Romney G, Desai N. Facial nerve palsy following mandibular setback: a case report and review of the literature. Am J Cosmetic Surg 2014;31:249-54.

8. Sakashita H, Miyata M, Miyamoto H, et al. Peripheral facial palsy after sagittal split ramus osteotomy for setback of the mandible: a case report. Int J Oral Maxillofac Surg 1996;25:182-3.

9. Lanigan DT, Hohn FI. Facial nerve injuries after sagittal split mandibular ramus osteotomies for advancement: a report of 2 cases and review of the literature. J Oral Maxillofac Surg 2004;62:503-7.

10. Sun DQ, Andresen NS, Gantz BJ. Surgical management of acute facial palsy. Otolaryngol Clin North Am 2018;51:1077-92.

11. Omura T, Sano M, Omura K, et al. A mild acute compression induces neurapraxia in rat sciatic nerve. Int J Neurosci 2004;114:1561-72.

12. Kitao A, Hirata $\mathrm{H}$, Morita $\mathrm{A}$, et al. Transient damage to the axonal transport system without Wallerian degeneration by acute nerve compression. Exp Neurol 1997;147:248-55. 